\title{
Involvement of nucleophosmin/B23 in TPA-induced megakaryocytic differentiation of K562 cells
}

\author{
CY Hsu' and BYM Yung ${ }^{*, 2}$ \\ 'Graduate Institute of Pharmacology, National Yang Ming University, Taiwan, Republic of China; ${ }^{2}$ Genomics Research Center \& Cancer Biochemistry \\ Laboratory, Department of Pharmacology, College of Medicine, Chang Gung University, 259 Wen-Hwa Ist Road, Kwei-San, Tao-Yuan 333, Taiwan, \\ Republic of China
}

Human myelogenous leukaemia K562 cells were induced to undergo megakaryocytic differentiation by treatment with phorbol ester 12-O-tetradecanoylphorbol-13-acetate (TPA) (20 nM, 24-72 h). The steady-state level of nucleophosmin/B23 mRNA decreased during the TPA-induced differentiation. There was also decrease in the level of cellular nucleophosmin/B23 protein and appearance of its degraded product $(25 \mathrm{kDa})$ during the TPA-induced differentiation. Furthermore, K562/B23 (wild type), K562/DI ( $\Delta 280-294$ )

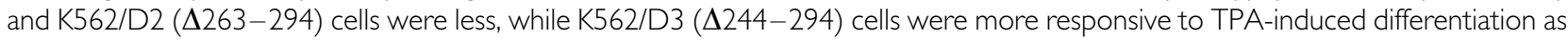
compared to K562/vector or parental K562 cells. Activation of the ERK/MAPK was observed in parental K562 cells upon TPA treatment (5 nM, 5-30 min). As compared to K562/vector cells, less activation of ERK/MAPK was observed in K562/D2 cells, while ERK/MAPK was highly activated in K562/D3 cells upon TPA treatment. Our results indicate that nucleophosmin/B23 plays an important role in TPA-induced differentiation of K562 cells and the amino acids 244-294 at C-terminal of nucleophosmin/B23 could be an important site for regulation of cellular response to differentiation.

British Journal of Cancer (2003) 89, I320- 1326. doi:I0.1038/sj.bjc.660 I I00 www.bjcancer.com (C) 2003 Cancer Research UK

Keywords: nucleophosmin/B23; TPA; megakaryocytic differentiation

A coordination and balance between cell proliferation, differentiation and apoptosis is crucial for normal development and tissuesize homeostasis in the adult (Li and Yuan, 1999). Dysregulation of this tightly controlled mechanism of cell differentiation and apoptosis may result in cancer. Mutated cell survival and inappropriate proliferation, disrupting this balance, would be expected to contribute to oncogenesis (Wyllie, 1997). Tumour cells often acquire damage to genes that directly regulate cell growth to result in uncontrolled cell proliferation. The identification of genes and their products that are involved in response to growth stimuli is essential for understanding of the normal cell growth and its regulation (Wolff, 1997).

Between cancer and normal cells, one important difference is the hyperactivity and the pleomorphism of the nucleoli in cancer cells (Busch et al, 1963; Busch, 1990). The nucleolus includes many proteins such as enzymes for RNA synthesis (RNA polymerase I) and processing (exonuclease and endonuclease), the proteins of preribosomes and nonribosomal proteins (Prestayko et al, 1974). Recent reports have shown that nonribosomal proteins of the nucleolus participate in regulating nucleolar activity that is associated with cell growth (Valdez et al, 1994). Of the proteins found in elevated amounts in nucleoli of cancer cells, a nonribosomal protein nucleophosmin/B23 is present in one of the largest amounts on two-dimensional gel electrophoresis (Prestayko et al, 1974; Orrick et al 1973). Nucleophosmin/B23,

*Correspondence: Dr BYM Yung; E-mail: byung@mail.cgu.edu.tw Received 21 January 2003; revised 7 May 2003; accepted 8 May 2003 being more abundant in tumour cells than in normal resting cells, has a potential role in increased nucleolar activity that is necessary for cell proliferation (Feuerstein et al, 1988; Chan et al, 1989); a role as a cytoplasmic/nuclear shuttle protein (Borer et al, 1989); relieves transcription repression by YY1 (Inouye and Seto, 1994); binds nuclear and nucleolar localisation signals on the HIV Type 1 Rev protein (Fankhauser et al, 1991) and the human T-cell leukaemia virus-1-Rex protein (Adachi et al, 1993); binds cell cycle-regulated nucleolar protein p120 (Valdez et al, 1994); inhibits DNA-binding and transcriptional activity of interferon regulatory factor-1 (IRF-1), which is a tumour suppressor (Tanaka et al, 1994; Kondo et al, 1997). Nucleophosmin/B23 overexpression at the RNA and protein levels may contribute to the onset of cancer (Feuerstein et al, 1988; Chan et al, 1989; Kondo et al, 1997). Blockage of nucleophomin/B23 expression with its antisense oligonucleotides has shown that nucleophosmin/B23 is crucial for making cancer cells resistant to induction of differentiation and apoptosis (Hsu and Yung, 1998; Liu and Yung, 1998; You et al, 1999). It thus appears that an excess of nucleophosmin/B23 is an important cause of cancer and not just a consequence.

The K562 cell line was originally established from the pleural effusion of a patient with chronic myelogenous leukemia (CML) in the blastic phase (Tabilio et al, 1983). The K562 cell line can be induced to differentiate towards megakaryocytic differentiation by the phorbol ester 12-O-tetradecanoylphorbol-13-acetate (TPA) and resulted in loss of proliferative capacity (Alitalo, 1990). 12-Otetradecanoylphorbol-13-acetate likely activates pathways of signal transduction regulating cell proliferation and differentiation. K562 cell line becomes an important tool for the study of early events 
involved in megakaryocytic differentiation. The aim of our present study was to investigate the role of nucleophosmin/B23 in megakaryocytic differentiation. Attempt was made to elucidate the effect of C-terminal deletion of nucleophosmin/B23 on TPAinduced differentiation of K562 cells. Our results demonstrate that nucleophosmin/B23 plays a role in the control of cellular response to TPA-induced megakaryocytic differentiation of K562 cells.

\section{MATERIALS AND METHODS}

\section{Drugs and antibodies}

12-O-tetradecanoylphorbol-13-acetate was purchased from Sigma Chemical Co. (St Louis, MO, USA). Monoclonal anti-phospho-ERK and anti-ERK antibodies (Abs) were from Santa Cruz (Santa Cruz, CA, USA). Monoclonal anti-CD41a-FITC and anti-CD42b-FITC Abs were purchased from BD Pharmingen (San Diego, CA, USA). Antiactin, anti-FLAG and fluorescein-conjugated goat anti-mouse IgG Abs were from Sigma. Monoclonal Ab to nucleophosmin/B23 was kindly provided by Dr PK Chan, Department of Pharmacology, Baylor College of Medicine, Houston, TX, USA.

\section{Cell culture}

K562 leukaemia cells were grown in RPMI-1640 medium (Life Technologies, Rockville, MD, USA) supplemented with $10 \%$ heatinactivated foetal bovine serum (Hyclone, UT, USA), $2 \mathrm{~mm}$ glutamine, $50 \mathrm{U} \mathrm{ml}^{-1}$ penicillin and $50 \mu \mathrm{g} \mathrm{ml}^{-1}$ streptomycin in a $5 \%$ humidified incubator at $37^{\circ} \mathrm{C}$. K562 cells were treated with TPA $(80 \mathrm{nM})$. Every $24 \mathrm{~h}$ for 4 days, cultures were harvested and monitored for cell number by counting cell suspensions with haemocytometer. Cell viability was assessed by exclusion of $0.2 \%$ trypan blue.

\section{Assays of cellular differentiation}

TPA-induced megakaryocytic differentiation of K562 cells was assayed by measuring the expressions of differentiation-specific membrane antigens (CD41a and CD42b). Cells were washed and suspended in ice-cold PBS containing $10 \%$ foetal calf serum. AntiCD41a-FITC or anti-CD42b-FITC Ab was added for 30 min at $4{ }^{\circ} \mathrm{C}$ and the cells were then washed twice with $2 \mathrm{ml}$ of PBS containing $10 \%$ foetal calf serum. The percentages of CD41a- or CD42bpositive cells and fluorescence intensities were evaluated by FACScan. The threshold value discriminating positive from negative cells was set as the fluorescence level below which $95 \%$ of control (TPA untreated) cells occurred.

\section{Immunoblot analysis}

Cells were harvested, washed twice in ice-cold PBS and lysed in RIPA buffer ( $1 \%$ Triton X-100, $1 \%$ sodium deoxycholate, $0.1 \%$ SDS, $20 \mathrm{mM} \mathrm{Na}_{2} \mathrm{HPO}_{4}, 100 \mathrm{~mm} \mathrm{NaCl}, 20 \mathrm{~mm} \mathrm{NaF}, 0.2 \mathrm{~mm}$ PMSF, $1 \mathrm{~mm}$ DTT, $30 \mu \mathrm{g} \mathrm{ml}^{-1}$ DNase and $30 \mu \mathrm{g} \mathrm{ml}^{-1}$ RNase). The lysates were boiled in SDS sample buffer $(62.5 \mathrm{~mm}$ Tris, $\mathrm{pH} 6.8,5 \% \beta$ mercaptoethanol, $10 \%$ glycerol, $2 \%$ SDS, $0.001 \%$ bromophenol blue) and the cell extract was fractionated by $10 \%$ SDSpolyacrylamide gel electrophoresis (SDS-PAGE). The separated proteins in SDS-PAGE were electrotransferred to Hybond-PVDF membrane (Amersham Pharmacia). The PVDF membrane was then soaked in a blocking solution (5\% nonfat milk in TBST buffer (20 mM Tris-HCl, pH 7.5, 0.5 M NaCl, 0.1\% Tween 20)) for $1 \mathrm{~h}$ at room temperature. The soaked PVDF membrane was then incubated with primary antibody overnight at $4^{\circ} \mathrm{C}$, washed with TBST buffer three times for $15 \mathrm{~min}$ each and incubated at room temperature for $1 \mathrm{~h}$ in horseradish peroxidase-conjugated goat anti-mouse IgG Ab (Promega, Madison, WI, USA). The membrane was washed with TBST buffer three times for $15 \mathrm{~min}$ each.
Immunoreactivity was determined using the chromogenic development or the enhanced chemiluminescence reaction (ECL, Amersham).

\section{RNA analysis}

Total RNA was prepared from K562 cells by ULTRASPEC ${ }^{\mathrm{TM}}$ RNA Isolation System (Biotecx, Houston, TX, USA). For Northern blot analysis, aliquots of $5 \mu \mathrm{g}$ of RNA were separated by $1.2 \%$ formaldehyde agarose gel electrophoresis, transferred to nylon membranes (Amersham) by downward alkaline capillary method and fixed to the membrane by drying at $80^{\circ} \mathrm{C}$ for $30 \mathrm{~min}$. The nucleophosmin/B23 cDNA labelled with $\left[\alpha^{32} \mathrm{P}\right] \mathrm{dCTP}$ using a random primed kit (Promega, Madison, WI, USA) was employed as a probe for detection of homologous mRNA. Prehybridisation was carried out overnight at $42{ }^{\circ} \mathrm{C}$ in a solution containing $50 \%$ formamide, Denhardt's solution, $5 \times \mathrm{SSC}(1 \times \mathrm{SSC}=0.15 \mathrm{M} \mathrm{NaCl}$, $0.015 \mathrm{M}$ sodium citrate), $0.1 \%$ SDS, and $250 \mu \mathrm{g} \mathrm{ml}^{-1}$ denatured salmon sperm DNA. Radiolabelled probe at a specific activity of $1-2 \times 10^{8}$ c.p.m. $\mu \mathrm{l}^{-1}$ was hybridised with total RNA in the same solution for $24 \mathrm{~h}$ at $42^{\circ} \mathrm{C}$. Washing of the membranes for the probes was twice in $2 \times \mathrm{SSC}$ and $0.5 \% \mathrm{SDS}$ at $42^{\circ} \mathrm{C}$ for $10 \mathrm{~min}$, and once in $0.1 \times$ SSC and $0.5 \%$ SDS at room temperature for $30 \mathrm{~min}$. The radioactive nucleophosmin/B23 homologous mRNA was determined by autoradiography with phosphoimager or with intensifying screen at $-70^{\circ} \mathrm{C}$.

\section{Plasmid}

Full-length nucleophosmin/B23 cDNA in plasmid PET-T7 (which was generously given by Dr Pui Kwong Chan, Department of Pharmacology, Baylor College of Medicine, Houston, TX, USA) was amplified by PCR using $5^{\prime}$-GCG TGC CGC CAC CCG ATG GAA GAT TCG ATG G- $3^{\prime}$ and $5^{\prime}$ - GTT TAA ACT ATT TTC TTA AAG AGA CTT- $3^{\prime}$ as primers. Amplified PCR products were then separated and isolated from $1 \%$ agarose gel. The 0.9 kilobase nucleophosmin/B23 cDNA was then subcloned into the cloning site of the vector $\mathrm{pCR}^{\mathrm{TM}} 3$ supplied in the Eukaryotic TA cloning kit (Invitrogene, Carlsbad, CA, USA). The orientation of the cDNA in $\mathrm{pCR}^{\mathrm{TM}} 3$ was determined by nucleotide sequencing using the Sequence kit (Amersham Pharmacia Biotech, Buckinghamshire, England, UK). The plasmid clones containing the nucleophosmin/ B23 cDNA in the sense orientation in respect to the cytomegalovirus $(\mathrm{CMV})$ immediate-early promoter of $\mathrm{pCR}^{\mathrm{TM}} 3$ was referred as pCR3-B23.

For full-length nucleophosmin/B23 cDNA clones (T7), the Nterminal primer was $5^{\prime}$ - ACC ATG GAC TAC AAA GAC GAT GAC GAC AAG CTT ATG GAA GAT TCG ATG GAC-3'. This primer encoded an AUG translation initiation codon followed by the codons for the eight amino acids in the FLAG epitope (Asp-TyrLys-Asp-Asp-Asp-Asp-Lys) and six amino acids from nucleophos$\mathrm{min} / \mathrm{B} 23$. The C-terminal primer that contained the BamHI site was $5^{\prime}$-CGC CGC GGA TCC TTA AAG AGA CTT CCT CCA CT-3'. For carboxyl-terminal deletion mutants, the $\mathrm{N}$-terminal primer was the same as T7 clone as described above. C-terminal primers were up to deletion sites and stop codon (TAA) was added in the terminus. The C-terminal primers for deletion mutants were: $\mathrm{D} 1$, $5^{\prime}$-GCG CCT AGG TTA AGT CAT CCG GAA GC-3' $(\Delta 280-294)$; D2, $5^{\prime}$-GCG CCT AGG TTA GGG AAG AGA ACC ACC- $3^{\prime}(\Delta 263-$ 294); D3, 5'-GCG CCT AGG TTA AGA ACT AGG TCC-3' $(\Delta 244-$ 294). Plasmid pET-T7 nucleophosmin/B23 cDNA was used as a template. After PCR amplification, the FLAG tag and the coding region of nucleophosmin/B23 should be in frame. The PCR products were cloned into pCR3.1 vector supplied in Eukaryotic TA cloning kit (Invitrogene, Carlsbad, CA, USA). The orientation of each construct was analysed by restriction mapping and fulllength nucleotide sequencing using the Sequence kit (Amersham Pharmacia Biotech). The plasmid clones containing the full-length 
nucleophosmin/B23 or deletion mutant cDNA were driven by CMV immediate-early promoter.

\section{Establishment of stable clones}

The transfection was performed using Lipofectamine ${ }^{\mathrm{TM}}$ Reagent (Life Technologies) method. K562 cells were seeded at a density of $5 \times 10^{5}$ per well in $1.0 \mathrm{ml}$ serum-free medium. A measure of $2.5 \mu \mathrm{g}$ of pCR3.1-FLAG-B23, pCR3.1-FLAG-D1, pCR3.1-FLAG-D2, pCR3.1-FLAG-D3 plasmid constructs or pCR3 vector alone and $12.5 \mu \mathrm{g}$ of lipofectamine reagents in serum-free medium were mixed gently. The mixture was incubated for $30 \mathrm{~min}$ at room temperature, added to K562 cells and was incubated overnight at $37^{\circ} \mathrm{C}$ in the $\mathrm{CO}_{2}$ incubator. The culture was further incubated in fresh RPMI-1640 medium for $48 \mathrm{~h}$. The transfected cells were then distributed in 24-well plates at 500 cells per well, and $800 \mu \mathrm{g} \mathrm{ml}^{-1}$ G418 was added for selection of stably transfected clones. After selection with G418 for 3-5 weeks, individual clones were expanded to mass cultures and subsequently assayed for nucleophosmin/B23 or its deletion mutant expression. The transfectants were maintained in culture medium supplemented with $200 \mu \mathrm{g} \mathrm{ml}^{-1}$ of G418. Clones overexpressing nucleophosmin/ B23 or its deletion mutants were screened by Western blot using monoclonal anti-FLAG Ab.

\section{RESULTS}

Decrease of nucleophosmin/B23 mRNA during TPA-induced differentiation of $\mathrm{K} 562$ cells

To investigate whether nucleophosmin/B23 was involved in megakaryocytic differentiation, we first examined nucleophosmin/B23 mRNA expression during TPA-induced differentiation of human myelogenous leukaemia K562 cells. K562 cells can be induced to differentiate towards megakaryocytic lineage, characterised by changes in cell morphology, cell growth arrest and acquisition of megakaryocytic surface markers (Braverman et al, 1986; Alitalo, 1990). Culturing the cells for $24-72 \mathrm{~h}$ with $20 \mathrm{~nm}$ TPA caused growth inhibition (Figure 1A) and a marked increase in differentiation surface marker, CD41a or CD42b (Figure 1B, C). The viability of the cells was over $90 \%$ as measured by trypan blue method over $72 \mathrm{~h}$ of $20 \mathrm{nM}$ TPA treatment (data not shown). A single mRNA band hybridizing with nucleophosmin/B23 cDNA probe was observed in Northern blot of rapidly proliferating leukaemic K562 cells (Figure 2). After $72 \mathrm{~h}$ of $20 \mathrm{~nm}$ TPA treatment, nucleophosmin/B23 mRNA expression decreased to less than $20 \%$. In parallel, $c-m y c$ mRNA expression was also decreased during TPA-induced differentiation (Figure 2).

Decrease of nucleophosmin/B23 protein level during TPAinduced differentiation of K562 cells

Total cellular protein samples (containing equal amounts of protein) from control untreated K562 cells and the K562 cells treated with 20 or $40 \mathrm{nM}$ TPA for various times ( $1-3$ days; $3-48 \mathrm{~h}$ ) were separated by $10 \%$ SDS - PAGE and subsequently analysed by Western blot immunoassay. The lower and upper panels of Figure $3 \mathrm{~A}$ or $\mathrm{B}$ showed the Coomassie blue-stained SDS-PAGE and chromogenic diagrams of Western blot analysis, respectively. After 1-3 days of TPA $(20-40 \mathrm{nM})$ treatment, the Western blot showed that the cellular protein level of nucleophosmin/B23 decreased and a new band at $25 \mathrm{kDa}$ appeared (Figure $3 \mathrm{~A}$ ). The appearance of $25 \mathrm{kDa}$ band was detected after $18 \mathrm{~h}$ of $20 \mathrm{nM}$ TPA treatment (Figure 3B). Caspase-3 inhibitor ( $25 \mu \mathrm{M}$; Ac-DEVD-CHO) blocked the decrease of nucleophosmin/B23 and the appearance of the new band at $25 \mathrm{kDa}$ that could possibly be the degraded form of nucleophosmin/B23 (data not shown).
A

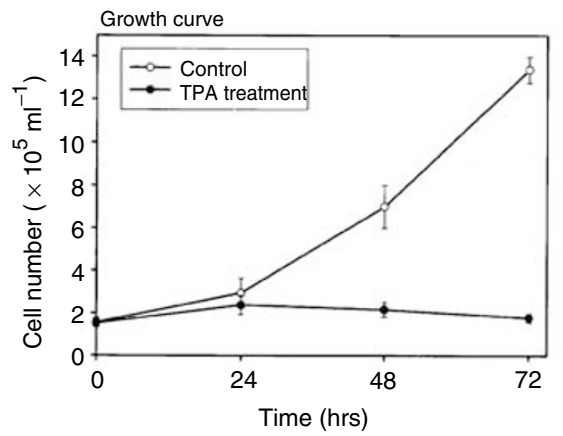

B
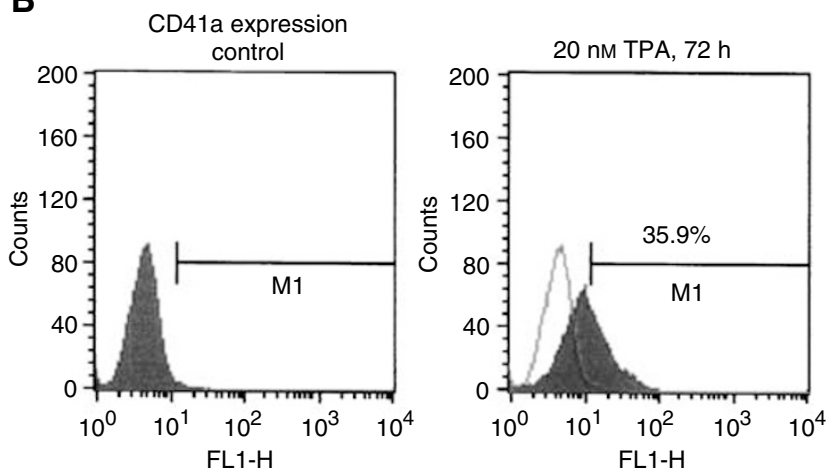

C
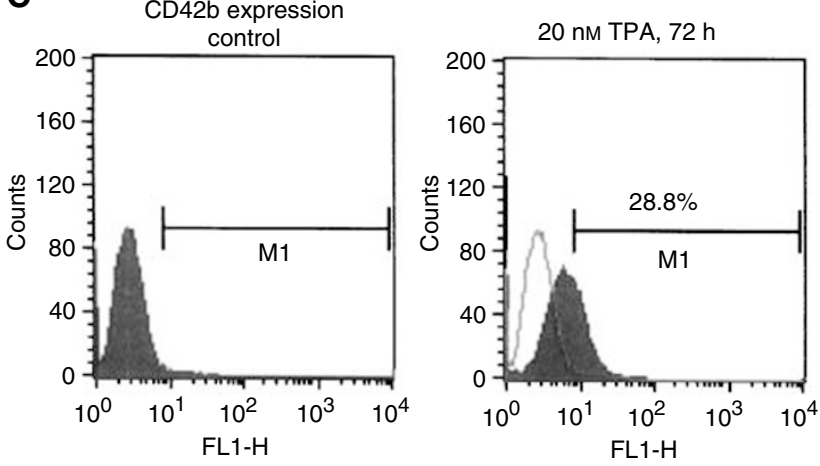

Figure I Effect of TPA on cell growth and differentiation of K562 cells. (A) The growth curve after $20 \mathrm{nM}$ TPA treatment for various times (24$72 \mathrm{~h}$ ). Cultures were harvested and cell numbers were counted with a haemocytometer. Points, means of triplicate \pm SD. Viability of the cells was $>90 \%$ under these TPA treatments. (B.C) K562 cells were treated with $20 \mathrm{nM}$ TPA for $72 \mathrm{~h}$ and the differentiation was assayed by measuring the expressions of differentiation markers. Expressions of the CD4la or CD42b were evaluated by flow cytometry using specific anti-CD4la or anti-CD42b FITC-conjugated monoclonal antibody.

\section{Establishment of nucleophosmin/B23 wild-type and deletion mutants overexpressed stable clones}

Attempt was made to investigate which domain of nucleophosmin/ B23 was involved in TPA-induced differentiation of K562 cells. K562 cells were transfected with nucleophosmin/B23 wild-type or deletion constructs fused each at its amino terminus to the FLAG epitope, encoding eight amino acids (Asp-Tyr-Lys-Asp-Asp-AspAsp-Lys) (Figure 4A). After G418 selection, stable clones of K562 cells overexpressing nucleophosmin/B23 wild-type and various deletion constructs, namely K562/B23 (wild type), K562/D1

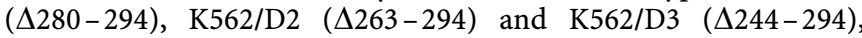
were established. We obtained two clones each from various stable clones of nucleophosmin/B23 wild-type or deletion mutants. Western blot analysis with anti-FLAG antibody showed that 


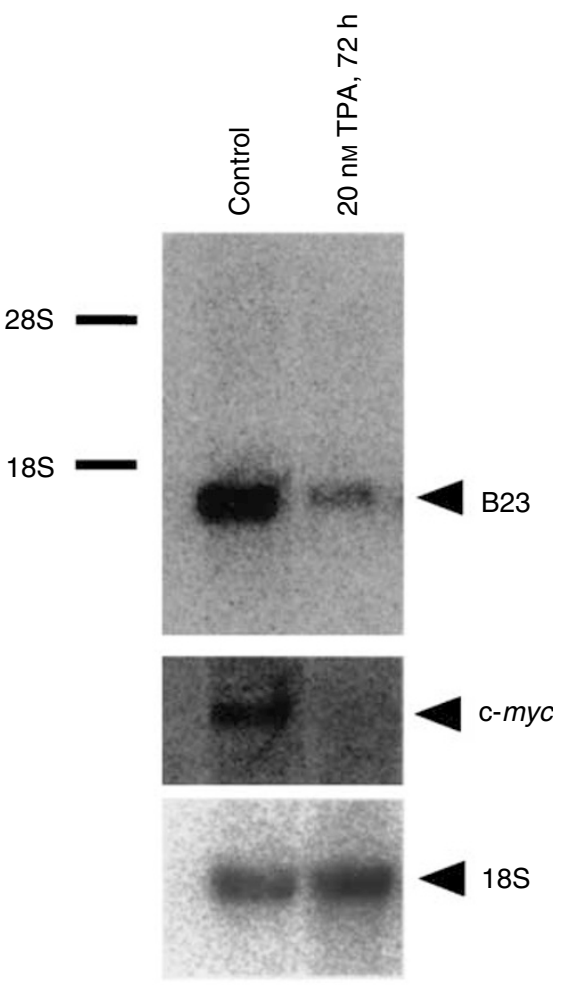

A

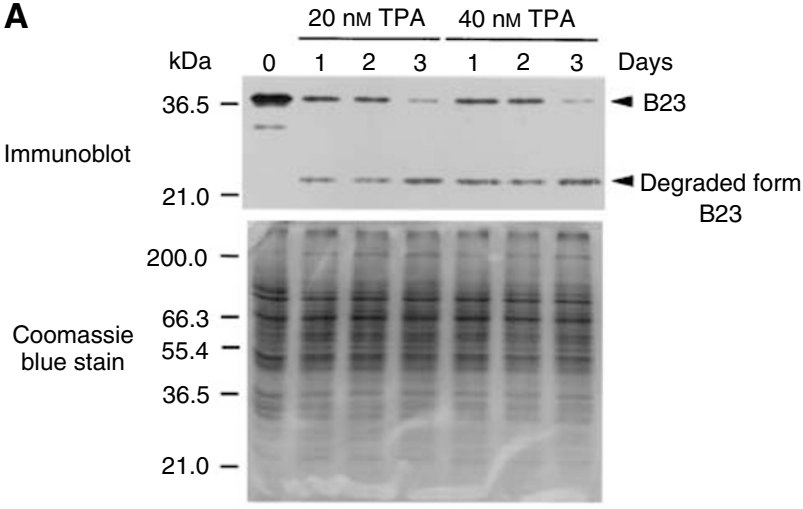

B

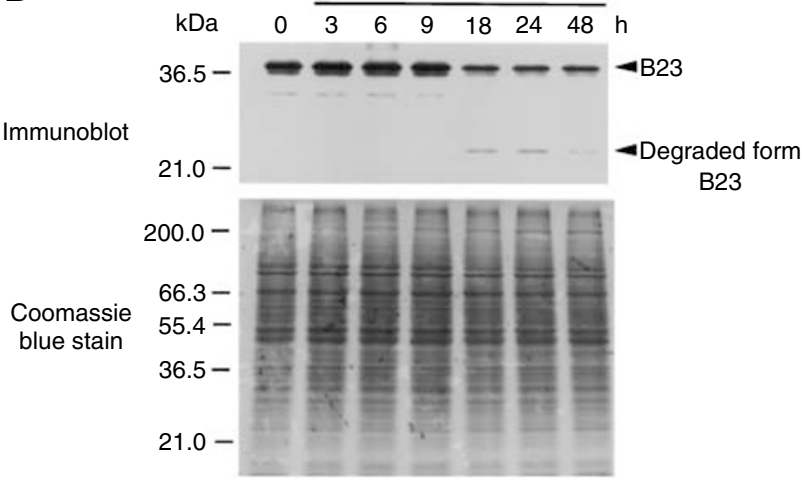

Figure 2 Decrease of nucleophosmin/B23 mRNA during TPA-induced differentiation of $\mathrm{K} 562$ cells. $\mathrm{K} 562$ cells were treated with 20 nM TPA for $72 \mathrm{~h}$. Cells were then harvested and the total RNA was prepared. Northern blot analysis was performed with $5 \mu$ g of RNA for each sample. The ${ }^{32}$ P-labelled nucleophosmin/B23 (B23) cDNA and c-myc probes were employed for detection of homologous mRNA. The same filter was hybridised with ${ }^{32} \mathrm{P}$-labelled I8S CDNA probe that was used as a control for the amount of RNA loaded.

nucleophosmin/B23 wild-type and deletion proteins were overexpressed in those stable clones (Figure 4B) and were distinguishable from cellular endogenous nucleophosmin/B23. The apparent mobility of the proteins corresponded well with the predicted molecular weight of each deletion mutant. The predicted sizes were as followed: FLAG-nucleophosmin/B23, $39 \mathrm{kDa}$; FLAG-D1, $36 \mathrm{kDa}$; FLAG-D2, 35 kDa; FLAG-D3, 33 kDa. K562/B23, K562/D1, K562/D2 and K562/D3 cells grew similarly and showed no morphological changes as compared with the control vector-transfected K562 cells (K562/vector) or the parental cells (K562 cells) (data not shown).

\section{Assessment of cellular response of nucleophosmin/B23 wild-type and deletion mutant overexpressed cells to TPA-induced differentiation}

Flow cytometric analysis of surface markers showed that expression of CD41a or CD42b was lower in K562/B23 (wild type), K562/ D1 $(\Delta 280-294)$ or $\mathrm{K} 562 / \mathrm{D} 2(\Delta 263-294)$ cells as compared to control vector-transfected cells (K562/vector) or the parental cells (K562 cells) treated with $20 \mathrm{~nm}$ TPA for $72 \mathrm{~h}$ (Figure 5). In contrast, expression of CD42b was higher in K562/D3 ( $\Delta 244-294)$ cells as compared to K562/vector or parental K562 cells treated with $20 \mathrm{nM}$ TPA for $72 \mathrm{~h}$ (Figure 5). Our results showed that K562/B23 (wild type), K562/D1 $(\Delta 280-294)$ and K562/D2 $(\Delta 263-294)$ cells were less, while K562/D3 $(\Delta 244-294)$ cells were more responsive to TPA-induced differentiation as compared to K562/vector or parental K562 cells. These results indicated that amino acids 244-294 of the nucleophosmin/B23 protein could be an important site for regulation of cellular response to differentiation. It is possible that deletion of C-terminal (amino acids 244-262) of
Figure 3 Decrease of nucleophosmin/B23 protein level during TPAinduced differentiation of $\mathrm{K} 562$ cells. (A) K562 cells were treated with 20 or $40 \mathrm{nM}$ TPA for various times ( $1-3$ days) or (B) treated with $20 \mathrm{nM}$ TPA for various times $(3-48 \mathrm{~h})$. Cells were harvested and $10 \mu \mathrm{g}$ of total cellular proteins was separated by 10\% SDS-PAGE stained with Coomassie blue (lower panels) or blotted onto PVDF membrane (upper panels). Nucleophosmin/B23 (B23) protein was detected by Immunoblot using anti-nucleophosmin/B23 monoclonal Ab and the chromogenic development.

nucleophosmin/B23 leads to the loss of its binding ability with some regulatory factor(s). The factor(s) being free from complexing with nucleophosmin/B23 is then functional for induction of differentiation.

\section{Activation of ERK upon TPA treatment}

Previous studies have shown that ERK/MAPK is activated during megakaryocytic differentiation of K562 cells (Racke et al, 1997; Whalen et al, 1997). To elucidate whether nucleophosmin/B23 was involved with ERK/MAPK in TPA-induced differentiation, we examined the effect of TPA on ERK activation in nucleophosmin/ B23 deletion mutant overexpressed K562/D2 (less responsive to TPA) and K562/D3 (more responsive to TPA) cells as compared to K562/vector cells (Figure 6). Activation of the ERK/MAPK was observed in parental K562 cells upon TPA treatment (5 nM, 5$30 \mathrm{~min}$ ) (Figure 6A). As compared to K562/vector cells, less activation of ERK/MAPK was observed in K562/D2 cells, while ERK/MAPK was highly activated in K562/D3 cells upon TPA treatment (5 $\mathrm{nM}, 10 \mathrm{~min}$ ) (Figure 6B).

\section{DISCUSSION}

This study investigated the possibility that nucleophosmin/B23 played an important role in cellular susceptibility to TPA-induced megakaryocytic differentiation of K562 cells. We demonstrate that 
A

\begin{tabular}{|c|c|c|}
\hline FLAG-B23 & $\begin{array}{r}1 \\
\text { FLAG } \\
\end{array}$ & $\square^{294}$ \\
\hline FLAG-D1 & $\begin{array}{r}1 \\
\text { FLAG }\end{array}$ & 279 \\
\hline FLAG-D2 & $\begin{array}{r}1 \\
\text { FLAG } \\
\end{array}$ & 262 \\
\hline FLAG-D3 & $\begin{array}{r}1 \\
\text { FLAG }\end{array}$ & 243 \\
\hline
\end{tabular}

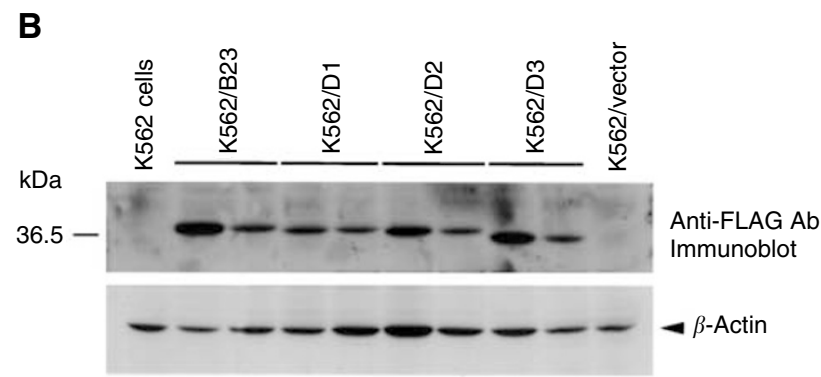

Figure 4 Schematic representation of nucleophosmin/B23 wild-type and deletion mutants. (A) The human nucleophosmin/B23 cDNA or its deletion mutants were cloned into the expression vectors PCR3.I in frame with the amino terminus of the FLAG epitope (Asp-Tyr-Lys-Asp-Asp-AspAsp-Lys). The first and last amino acids residues are indicated by numbers. The open boxes represent the open reading frame of nucleophosmin/B23 wild-type and deletion mutants. (B) Immunoblot analysis of overexpression of nucleophosmin/B23 wild-type or deletion mutants in stable clones of K562 cells. Total protein was extracted from the parental K562 cells, the control vector-transfected K562 cells (K562/vector) and stable clones (two for each) of nucleophosmin/B23 wild-type (K562/B23) or deletion mutants (K562DI-D3). A measure of $50 \mu \mathrm{g}$ of total cellular proteins was separated by $10 \%$ SDS-PAGE and blotted onto PVDF membrane. FLAG-wild-type nucleophosmin/B23 (FLAG-B23), FLAG-DI, FLAG-D2, FLAG-D3 or $\beta$ actin protein was detected by Western blot using anti-FLAG or anti- $\beta$-actin monoclonal antibody. Immunoreactivity was determined by the ECL reaction.

nucleophosmin/B23 mRNA and protein are decreased after TPA treatment in parental K562 cells. Stable clones of K562 cells overexpressing nucleophosmin/B23 wild-type and various deletion constructs, namely K562/B23 (wild type), K562/D1 ( $\Delta 280-294)$, K562/D2 $(\Delta 263-294)$ and K562/D3 $(\Delta 244-294)$ have been established to investigate which domain of nucleophosmin/B23 is involved in TPA-induced differentiation of K562 cells. Our results have shown that K562/B23 (wild type), K562/D1 $(\Delta 280-294)$ and K562/D2 $(\Delta 263-294)$ cells are less, while K562/D3 $(\Delta 244-294)$ cells are more responsive to TPA-induced differentiation as compared to K562/vector or parental K562 cells. These results indicate that amino acids 244-294 of the nucleophosmin/B23 protein may be an important site for regulation of cellular response to TPA-induced differentiation of K562 cells. C-terminal end has been shown to be important site of nucleophosmin/B23. DNA polymerase $\alpha$ binding site is at the C-terminal. A total of 12 amino acids at the C-terminal end of B23.1, which are absent in B23.2, is essential for full stimulation of the DNA polymerase $\alpha$ (Umekawa et al, 2001). Deletion of C-terminal (amino acids 244 262) of nucleophosmin/B23 may lead to the loss of its binding ability with important growth regulatory factor(s). Stimulation of growth activity was inhibited or factor(s) being free from complexing with nucleophosmin/B23 is then functional for induction of differentiation.

In RA-induced differentiation of HL-60 cells, the involvement of nucleophosmin/B23 in oncogenic activity is that nucleophosmin/ B23 may bind and inactivate the tumour suppressor in cancer cells
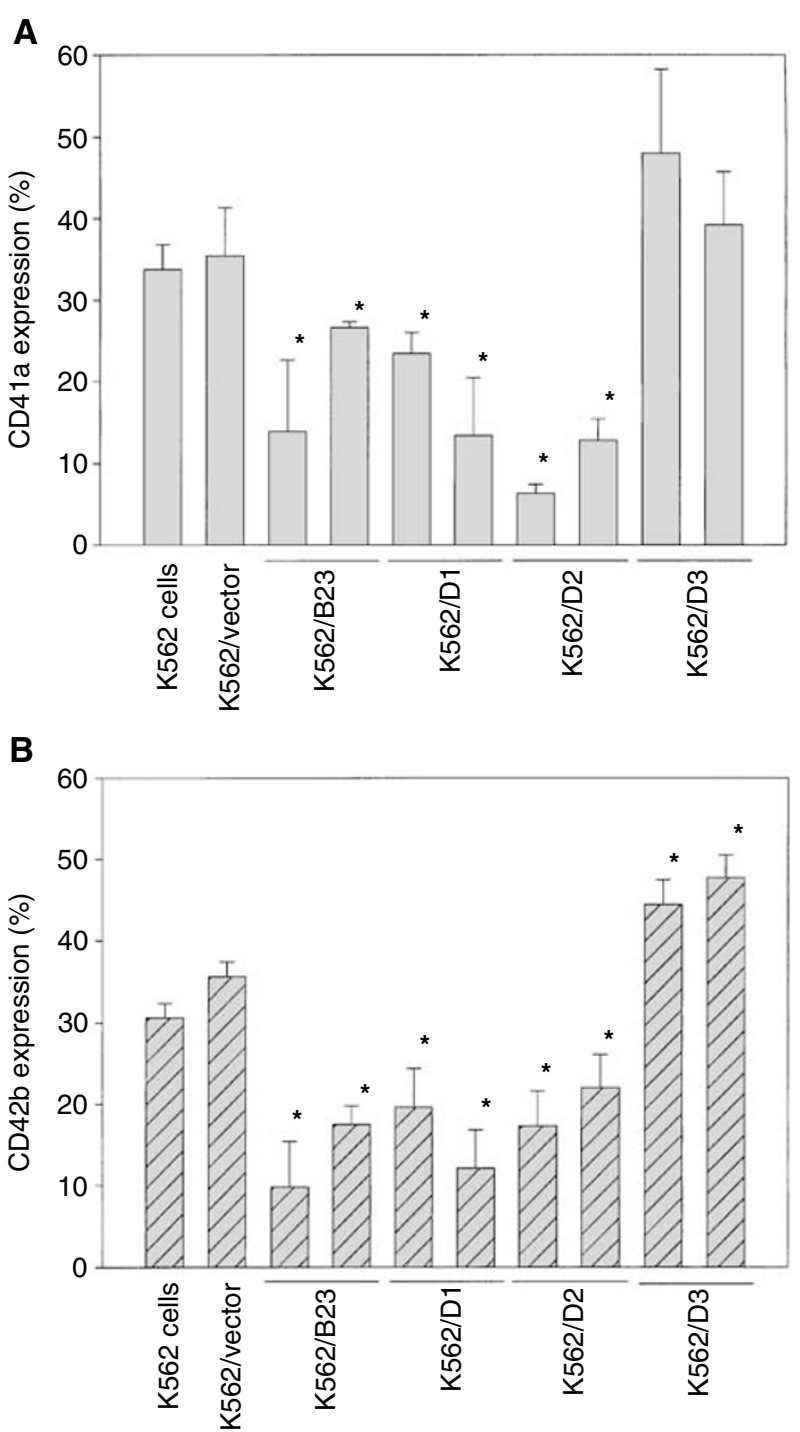

Figure 5 Assessment of cellular response of nucleophosmin/B23 wildtype and deletion mutant overexpressed cells to TPA-induced differentiation. The parental K562 cells, the control vector-transfected K562 cells (K562/vector) and the stable clones (two for each) of nucleophosmin/B23 wild-type (K562/B23) or deletion mutants (K562/DI, K562/D2 or K562/ D3) were treated with $20 \mathrm{nM}$ TPA for $72 \mathrm{~h}$. After the cells were harvested, expressions of CD4la (A) or CD42b (B) were evaluated by flow cytometry using specific anti-CD4la or anti-CD42b FITC-conjugated monoclonal antibody. Bars, means of triplicate $\pm S D$. $* P<0.05$, as compared with K562/vector cells under same TPA treatment.

(Hsu and Yung, 2000). IRF-1 acts as a transcriptional activator in the interferon system and as a tumour suppressor (Harada et al, 1989,1993). Nucleophosmin/B23 could bind to IRF-1, interfere with IRF-1 binding to IRF-1 response elements, inhibit the IRF-1 transcriptional activity and manifest oncogenic potential (Kondo et al, 1997; Hsu and Yung, 2000). Interaction of nucleophosmin/ B23 with some factor(s), such as tumour suppressor, may be an important mechanism in the control of cellular response to induction of cellular differentiation and apoptosis. The availability of the binding site of nucleophosmin/B23 to interact with tumour suppressor is the basis for the cells being abnormal and resistant to induction of differentiation and apoptosis. In the present study, little induction of IRF-1 protein was observed in TPA-induced differentiation of K562 cells. All GST-nucleophosmin/B23 and the deletion mutants (D1-D3) could bind the in vitro translated ${ }^{35} \mathrm{~S}$ 
A

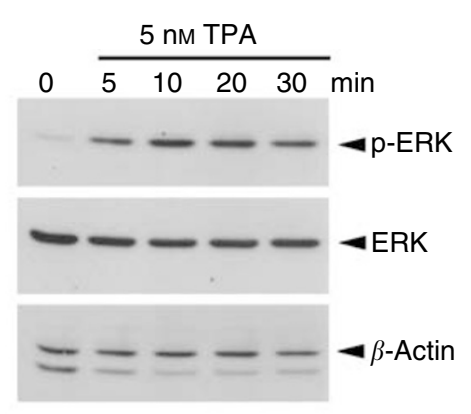

B

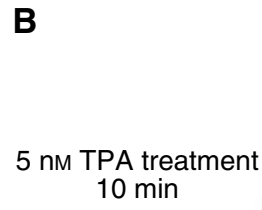

ERK/MAPK activation (fold of

K562/vector control)

Figure 6 Immunoblot analysis of activated ERK ( $p$-ERK) or total ERK level upon TPA treatment. (A) K562 cells were treated with 5 nM TPA for various times (5-30 min). (B) K562/D2, K562/D3 or the control K562/ vector cells (two lanes for each stable clone) were treated with 5 nM TPA for $10 \mathrm{~min}$. Cells were harvested and $20 \mu \mathrm{g}$ of total cellular proteins was separated by $10 \%$ SDS-PAGE and blotted onto PVDF membrane. p-ERK, ERK (total) or $\beta$-actin protein were detected by Western blot using anti-pERK, ERK or $\beta$-actin monoclonal antibody and the ECL reaction.

IRF-1 (our unpublished data). Nucleophosmin/B23 may act through other factors rather than IRF-1 in the control of TPAinduced differentiation in $\mathrm{K} 562$ cells.

Decrease of nucleophosmin/B23 has been observed in cells during induction of cellular differentiation and apoptosis (Hsu and Yung, 1998; Liu and Yung 1998). More drastic decrease of nucleophosmin/B23 is detected in NIH-3T3 than in ras-transformed cells during the apoptosis induced by serum deprivation (Chou and Yung, 2001). Nucleophosmin/B23 in serum-deprived NIH-3T3 cells is found to be highly unstable, with a half-life of less than $4 \mathrm{~h}$. Cell-permeable caspase- 3 inhibitor $(10-25 \mu \mathrm{M})$ blocks the decrease of nucleophosmin/B23 induced by serum deprivation in NIH-3T3 cells (Chou and Yung, 2001). These studies indicate that increased stability of nucleophosmin/B23 is involved in antiapoptosis. While no evidence of cleavage of nucleophosmin/B23 under apoptotic or necrotic conditions was found in HL-60 cells before (Bortul et al, 2001), the appearance of its degraded forms has now been detected in serum-deprived NIH-3T3 (Chou and Yung, 2001) and TPA-treated K562 cells (the present study). Signalling pathway and cell specificity involved with the cleavage of nucleophosmin/ B23 in the induction of apoptosis and differentiation need further investigation.

Mitogen-activated protein kinase (MAPK) modules are involved in the signal transduction of a wide variety of signals in the eukaryotic organisms. The ERK/MAPK cascade plays a pivotal role in several cellular functions. The ERK/MAPK is activated by dual phosphorylation on a threonine and a tyrosine residue, achieved by the dual-specificity kinase MAP kinase kinase (MEK) (Waskiewicz and Cooper, 1995). In our present study, activation of the ERK/MAPK is observed in parental K562 cells upon TPA treatment. As compared to K562/vector cells, less activation of ERK/MAPK is observed in K562/D2 cells, while ERK/MAPK is highly activated in K562/D3 cells upon TPA treatment. Our results indicate that nucleophosmin/B23 plays a role in cellular response to ERK/MAPK-activated megakaryocytic differentiation of K562 cells.

Nucleolus participates in many other aspects of gene expression as well (Pederson, 1998). Biosyntheses of signal recognition particle RNA and telomerase RNA involve a nucleolar stage (Pederson, 1998) and nucleolus is a site critical to cellular aging (Johnson et al, 1998). Nucleolar protein nucleophosmin/B23 is importantly associated with cancer (You et al, 1999) and is implicated to have a functional role in the apoptotic cascade (Patterson et al., 1995) and growth control (Hsu and Yung, 1998; Liu and Yung, 1998). The potentiation ability of nucleophosmin/ B23 antisense in induced cellular differentiation, apoptosis and inhibition of telomerase activity is particularly interesting and may lead to the use of antisense construct in cancer treatment. Taken together, the present study represents one of the few demonstrations of the involvement of a nuclear protein in the control of cell death/cell differentiation. The detailed mechanism or transduction cascade involved in nucleophosmin/B23-mediated resistance to induction of differentiation and apoptosis is under current investigation.

In conclusion, our results provide evidence that nucleophosmin/ B23 plays an important role in TPA-induced megakaryocytic differentiation of K562 cells.

\section{ACKNOWLEDGEMENTS}

This work was supported by Chang Gung Memorial Hospital Research Grant CMRP 997-III ; National Science Council (ROC) Grant NSC 91-2320-B182-001 and National Research Institute of Health Council (ROC) Grant NHRI-GT-EX91-8935SL.

\section{REFERENCES}

Adachi Y, Copeland TD, Hatanaka M, Oroszlan S (1993) Nucleolar targeting signal of Rex protein of human T-cell leukemia virus type I specifically binds to nucleolar shuttle protein B23. J Biol Chem 268: $13930-13934$

Alitalo R (1990) Induced differentiation of K562 leukemia cells: a model for studies of gene expression in early megakaryoblasts. Leukemia Res 14: $501-514$

Borer RA, Lehner CF, Eppenberger HM, Nigg EA (1989) Major nucleolar proteins shuttle between nucleus and cytoplasm. Cell 56: $379-390$
Bortul R, Zweyer M, Billi AM, Tabellini G, Ochs, RL, Bareggi R, Cocco L, Martelli AM (2001) Nuclear changes in necrotic HL-60 cells. J Cell Biochem 81: 19-31

Braverman R, Bhattacharya B, Feuerstein N, Cooper HL (1986) Identification and characterization of the nonphosphorylated precursor of $\mathrm{pp} 17$, a phosphoprotein associated with phorbol ester induction of growth arrest and monocytic differentiation in HL-60 promyelocytic leukemia cells. $J$ Biol Chem 261: $14342-14348$

Busch H (1990) The final common pathway of cancer: presidential address. Cancer Res 50: 4830-4838 
Busch H, Byvoet P, Smetana K (1963) The nucleolus of the cancer cell: review. Cancer Res 23: 313-339

Chan WY, Liu QR, Borjigin J, Bush H, Rennert R, Tease LA, Chan PK (1989) Characterization of the cDNA encoding human nucleophosmin and studies of its role in normal and abnormal growth. Biochemistry 28: $1033-1039$

Chou CC, Yung BYM (2001) Increased stability of nucleophosmin/B23 in anti-apoptotic effect of ras during serum deprivation. Mol Pharmacol 59: $38-45$

Fankhauser C, Izaurralde E, Adachi Y, Wingfield P, Laemmli UK (1991) Specific complex of human immunodeficiency virus type $1 \mathrm{Rev}$ and nucleolar B23 proteins: dissociation by the Rev response element. Mol Cell Biol 11: $2567-2575$

Feuerstein N, Spiegel S, Mond JJ (1988) The nuclear matrix protein, numatrin (B23), is associated with growth factor-induced mitogenesis in Swiss 3T3 fibroblasts and with T lymphocyte proliferation stimulated by lectins and anti-T cell antigen receptor antibody. J Cell Biol 107: 16291642

Harada H, Fujita T, Miyamoto M, Kimura Y, Maruyama M, Furia A, Miyata $\mathrm{T}$, Taniguchi $\mathrm{T}$ (1989) Structurally similar but functionally distinct factors, IRF-1 and IRF-2, bind to the same regulatory elements of IFN and IFN-inducible genes. Cell 58: 729-739

Harada H, Kitagawa M, Tanaka N, Yamamoto H, Harada K, Ishihara M, Taniguchi $\mathrm{T}$ (1993) Anti-oncogenic and oncogenic potentials of interferon regulatory factor-1 and -2 . Science 259: $971-974$

Hsu CY, Yung BYM (1998) Down-regulation of nucleophosmin/B23 during retinoic acid-induced differentiation of human promyelocytic leukemia HL-60 cells. Oncogene 16: 915 - 923

Hsu CY, Yung BYM (2000) Over-expression of nucleophosmin/B23 decreases the susceptibility of human leukemia HL-60 cells to retinoic acid-induced differentiation and apoptosis. Int J Cancer 88: $392-400$

Inouye CJ, Seto E (1994) Relief of YY1-induced transcriptional repression by protein - protein interaction with the nucleolar phosphoprotein B23. J Biol Chem 269: 6506-6510

Johnson FB, Marciniak RA, Guarente L (1998) Telomerase, the nucleolus and aging. Curr Opin Cell Biol 10: $332-338$

Kondo T, Minamino N, Nagamura-Inoue T, Matsumoto M, Taniguchi T, Tanaka N (1997) Identification and characterization of nucleophosmin/ B23/numatrin which binds the anti-oncogenic transcription factor IRF-1 and manifests oncogenic activity. Oncogene 15: 1275-1281

Li H, Yuan J (1999) Deciphering the pathways of life and death. Curr Opin Cell Biol 11: 261 - 266

Liu WH, Yung BYM (1998) Mortalization of human promyelocytic leukemia HL-60 cells to be more susceptible to sodium butyrate-induced apoptosis and inhibition of telomerase activity by down-regulation of nucleophosmin/B23. Oncogene 17: 3055-3064
Orrick LR, Olson MOJ, Busch H (1973) Comparison of nucleolar proteins of normal rat liver and Novikoff hepatoma ascites cells by two-dimensional polyacrylamide gel electrophoresis. Proc Natl Acad Sci USA 70: 13161320

Patterson SD, Grossman JS, Andrea PD, Latter GI (1995) Reduced numatrin/B23/nucleophosmin labeling in apoptotic Jurkat T-lymphoblasts. J Biol Chem 270: $9429-9436$

Pederson T (1998) The plurifunctional nucleolus. Nucleic Acids Res 26: $3871-3876$

Prestayko AW, Klomp GR, Schmoll DJ, Busch H (1974) Comparison of proteins of ribosomal subunits and nucleolar preribosomal particles from Novikoff hepatoma ascites cell by two-dimensional polyacrylamide gel electrophoresis. Biochemistry 13: $1945-1951$

Racke FK, Lewandowska K, Goueli S, Goldfarb AN (1997) Sustained activation of the extracellular signal-regulated kinase/mitogen-activated protein kinase pathway is required for megakaryocytic differentiation of K562 cells. I Biol Chem 272: $23366-23370$

Tabilio A, Pelicci PG, Vinci G, Mannoni P, Civin CI, Vainchenker W, Testa U, Lipinski M, Rochant H, Breton-Gorius J (1983) Myeloid and megakaryocytic properties of K-562 cell lines. Cancer Res 43: 4569-4574

Tanaka N, Ishihara M, Kitagawa M, Harada H, Kimura T, Matsuyama T, Mak TW, Taniguchi T (1994) Cellular commitment to oncogene-induced transformation or apoptosis is dependent on the transcription factor IRF-1. Cell 77: 829-839

Umekawa H, Sato K, Takemura M, Watanabe Y, Usui S, Takahashi T, Yoshida S, Olson MO, Furuichi Y (2001) The carboxyl terminal sequence of nucleolar protein B23.1 is important in its DNA polymerase $\alpha$ simulatory activity. $J$ Biochem 130: 99-205

Valdez BC, Perlaky L, Henning D, Saijo Y, Chan PK, Busch H (1994) Identification of the nuclear and nucleolar localization signals of the protein p120: interaction with translocation protein B23. J Biol Chem 269: $23776-23783$

Waskiewicz AJ, Cooper JA (1995) Mitogen and stress response pathways: MAP kinase cascades and phosphatase regulation in mammals and yeast. Curr Opin Cell Biol 7: 798-805

Whalen AM, Galasinski SC, Shapiro PS, Nahreini TS, Ahn NG (1997) Megakaryocytic differentiation induced by constitutive activation of mitogen-activated protein kinase kinase. Mol Cell Biol 17: 1947-1958

Wolff L (1997) Contribution of oncogenes and tumor suppressor genes to myeloid leukemia. Biochem Biophys Acta 1332: F67-F104

Wyllie AH (1997) Apoptosis and carcinogenesis. Eur J Cell Biol 73: $189-197$

You BJ, Huang IJ, Liu WH, Hung YB, Chang JH, Yung BYM (1999) Decrease in nucleophosmin/B23 mRNA and telomerase activity during indomethacin-induced apoptosis of gastric KATO-III cancer cells. Naunyn-Schmiedebergs Arch Pharmacol 360: 683-690 